\title{
The Yellow Lady's Slipper
}

\section{By Marion Nixon, Wauchope}

The yellow lady's slipper (Cypripedium calceolus $L$.) is found in our district in June, in favoured locations and wet seasons, in unexpected profusion. It grows on wild pasture: in the shelter between bluffs that are edging sloughs. After a series of wet summers, and especially after one autumn had created the ideal conditions for ripening and wind-sowing seed, we found yellow lady's slippers springing up every few feet, all across the gentle heights of land that separated various poplar-ringed sloughs on a half section of wild pasture. These individual plants increased rapidly in size with further favourable seasons. A single blossom to a stem is common, with two or three stems per root stalk. But when the wet seasons after 1944 gave them a prod into real profusion "a pair of slippers," both on a single stem, rewarded many a walk; at the same time, root formations spread in girth till they would send up six, eight, or occasionally ten leaf-cuddled stalks, each bearing its miniature yellow-kid moccasin. We found several that supported eighteen, and one even bore twenty blooms. This profusion continued until three years ago, when the water table under their habitat showed drastic recession.

Now this pasture is dry and heavily grazed, the sloughs are gone, and the lady's slipper meadows that so amazed and gratified us are shorn of their beauty. However, in our own adjoining field there is one wild corner, seldom grazed, which can be expected to explode back into profusion when once again the seasons so conspire.

I have been told that lady's slipper seed is virtually impossible for the amateur gardener to start. Certainly I have had no success. However, the plants move to a flower border quite easily, if care is taken to give them a natural habitat-sheltered from north winds, yet witr. plenty of sun, and with water nearby though not about their roots.

Because the flower stalk and leaf must be left to ripen down, storing their goodness in the root for the following year's growth, it is necessary to make a field trip in mid-
June to stake plants which one wishes to move. Then in early September, when another trip to lift them from amongst the overgrowth of grass is made, the stakes save endless time. Sharp eyes CAN pick out the tulip-shaped brown seed pod but only a few plants seem to set seed; the sere leaf is even more difficult to locate, so many other plants have used the sod since June.

The root is found three or four inches below the surface, and grows like a chunky mat an inch or so thick, with protruding short, fleshy roots that usually come up matted with clay. Many of these root mats are roughly. saucer size, a few attain the size of breakfast plates, but it is only rarely we find one, roughly oval, as much as ten inches long. This would be enough to bear 15 to 18 blooms.

There are two other orchids growing on our farm, the greenish longbracted orchid, Habenaria bracteata (Willd.) R.Br. and the saprophyte, Corallorhiza striata Lindl. The latter has disappeared again since the sloughs dried up which had provided the moisture to rot the willow and poplar deadfall upon which the coral root feeds.

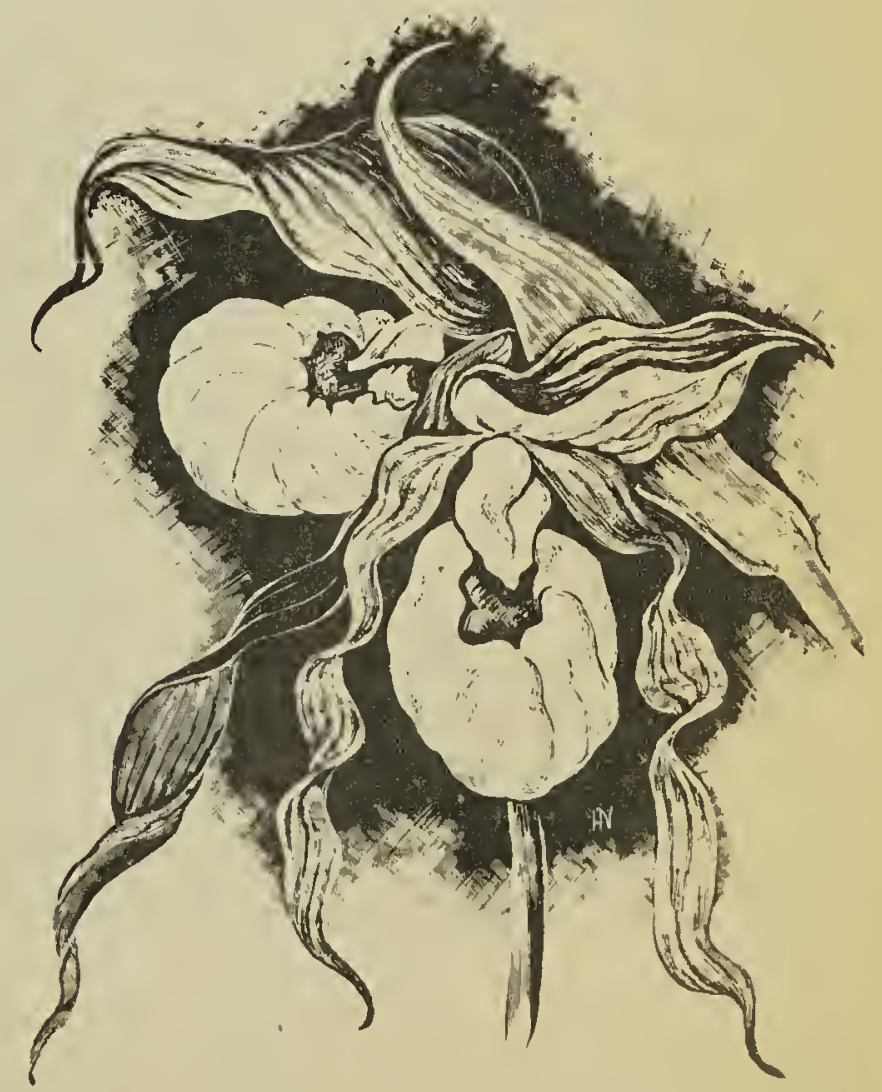

Sketch by Helen Nixon Yellow Lady's Slipper 